\title{
Sol Ana Koroner Artere Acil Girişim
}

\section{Emergency Intervention for Left Main Coronary Artery}

\section{Özge Çakmak Karaaslan, Salih Topal, Burak Sezenöz, Rıdvan Yalçın}

Gazi Üniversitesi Tıp Fakültesi Kardiyoloji Ana Bilim Dalı, Ankara, Türkiye

\section{ÖZET}

Sol ana koroner arter(LMCA) lezyonlarında öncelikli tedavi by-pass cerrahisi olarak değerlendirilirken, son yıllarda yapılan çalışmalar perkütan koroner girişimin(PKG) de alternatif olabileceğini vurgulamaktadır.[1, 2] 47 yaşında erkek hasta nefes darlı̆ıı ve senkop şikayeti ile merkezimize başvurdu. Koroner anjiografide(KAG); LMCA ostiumunda \%95 lik darlık oluşturan trombüslü komplike plak izlendi. Hasta acil koroner By-pass cerrahisi kararı verildi, o sırada kardiyak arrest gelişti, kardiyopulmoner ressüsitasyon (CPR) altında tekrar kateter laboratuvarına alındı. LMCA ya stent yerleştirildi. Mevcut vakada olduğu gibi kardiyak arrest veya kardiyojenik şok tablosu gelişen hastalarda olabildiğince hızlı müdahale etmek ve iskemi süresini kısaltmak amacıyla acil perkütan koroner girişim öncelikli tedavi seçeneği olarak düşünülebilir.

Anahtar Sözcükler: Sol ana koroner lezyonu, Perkütan Koroner Girişim, Acil Revaskülarizasyon

\section{ABSTRACT}

While the primary treatment for left main coronary artery(LMCA) lesions is considered as a by-pass surgery, recent studies indicate that percutaneous coronary intervention (PCI) may be an alternative. $[1,2]$ A 47-year-old male patient was admitted to our center with complaints of shortness of breath and syncope. KAG; In the left main coronary artery ostium, a $95 \%$ stenosis with a thrombus was observed. The patient was decided to undergo emergency coronary by-pass surgery, at that time developed cardiac arrest, was taken to the catheter laboratory under cardiopulmonary resuscitation (CPR). A stent was inserted into the LMCA. As in the present case, emergency percutaneous coronary intervention may be considered as the primary treatment option in patients who develop cardiac arrest or cardiogenic shock as fast as possible and shorten the duration of ischemia.

Key Words: Left main coronary lesion, Percutaneous Coronary Intervention, Emergency Revascularization

Received: 08.28.2018

Accepted: 12.24 .2018

\section{GiRiş}

Kardiyovasküler sistem (KVS) hastalıkları dünyada önde gelen mortalite ve morbidite nedenidir. KVS hastalıklarına bağlı ölümlerin en büyük kısmını ise koroner arter hastalığı (KAH) oluşturmaktadır(3). Sol ana koroner arter lezyonlarında öncelikli tedavi by-pass cerrahisi(CABG) olarak değerlendirilirken, son yıllarda yapılan çalışmalar perkütan koroner girişimin de alternatif olabileceğini vurgulamaktadır $(1,2)$. Sol ana koroner arter lezyonlarında ilk PKG 21 kasım 1977 de yapılmıştır ve yaklaşık 40 yıldır ilk yaklaşım olarak by-pass veya PKG tartışılmaktadır $(4,5)$.

\section{OLGU SUNUMU}

Kırk yedi yaşında erkek hasta nefes darlığı ve senkop şikayeti ile merkezimize başvurdu. Özgeçmişinde hipertansiyon, hiperlipidemi ve serebrovasküler olay öyküsü mevcuttu. Fizik muayenede belirgin patolojik özellik saptanmadı. Elektrokardiyografide sinüs ritmi, inferior derivasyonlarda $Q$ dalgası ve anterior derivasyonlarda $R$ dalga kaybı mevcuttu. Hastanın ekokardiyografisinde segmenter duvar hareket kusuru (ejeksiyon fraksiyonu \% 28) ve orta dereceli mitral yetersizlik saptandı. 
Laboratuar paremetrelerinde özellik olmayan hastaya intrakardiyak defibrilatör(ICD) planlanarak öncesinde koroner anjiyografi planladı. KAG de; LMCA ostiumunda \%95 lik darlık oluşturan trombüslü komplike plak izlendi (Şekil 1). D1 deki stentin açık olduğu Cx gövdede \% 50 darlık olduğu görüldü. Ayrıca RCA proksimalde tam tıkanıklık olduğu saptandı. Hasta acil koroner Bypass cerrahisi düşünülerek Kalp ve Damar Cerrahisi bölümüne danışıldı. Hemodinami laboratuvarında KVC bölümünce değerlendirilirken hastada kardiyak arrest tablosu gelişmesi üzerine hasta kardiyopulmoner ressüsitasyon altında tekrar kateter laboratuvarına alındı. 6F JL4 kateter ile sol ana koroner artere oturulduğunda LMCA nın tam tıkalı olduğu görüldü. CPR altında floopy tel LAD ye ilerletilerek $3.5 / 15 \mathrm{~mm}$ balon ile LMCA da predilatasyon yapıldı. Predilatasyon sonrası LMCA ya $4.5 / 16 \mathrm{~mm}$ stent yerleştirildi. Stent sonrası hastada sinüs ritmi sağlandı. Hasta işlem sonrası koroner yoğun bakıma alındı. Hemodinamisi tedricen düzelen ve genel durumu toparlayan hastanın ertesi gün yapılan ekokardiyografisinde ejeksiyon fraksiyonu Modifiye Simpson yöntemiyle \%38 olarak hesaplandı. Hastaya ikili antiagregan tedavi altında medikal tedavisi düzenlenerek 3 . günde taburcu edildi.

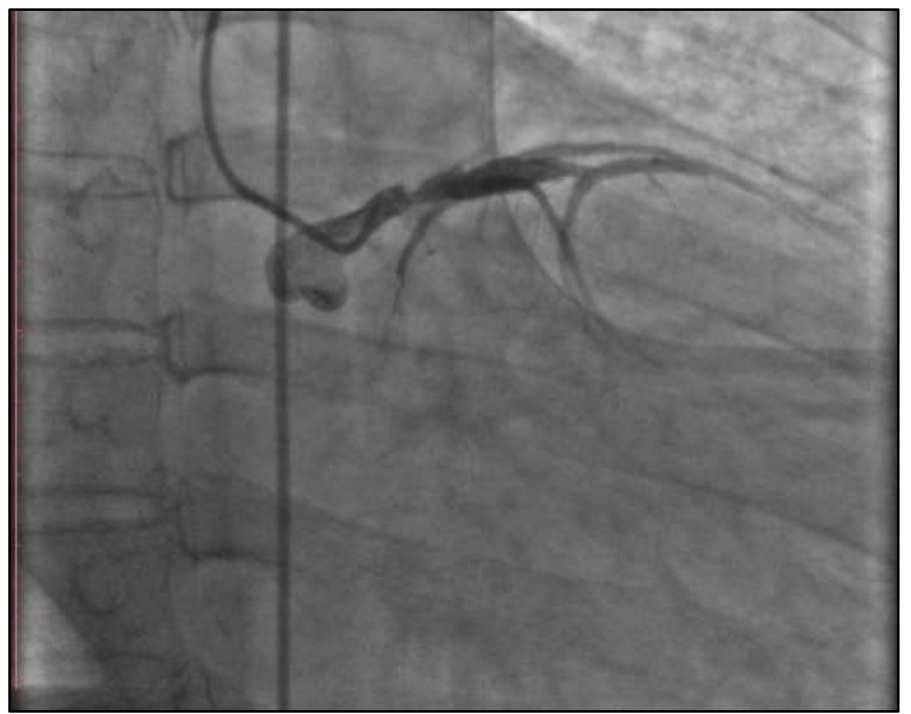

Şekil 1: Koroner anjiografi sırasında izlenen sol ana koroner arterde trombüslü komplike plak görünümü

\section{TARTIŞMA}

Sol ana koroner arter lezyonlarına bağlı akut miyokard enfarktüsü vakalarının mortalitesi yüksek olmakla beraber, yapılan çalışmalar uzun dönem takiplerde koroner bypass cerrahisinin sonuçlarının daha iyi olduğu bilinmektedir(6). Yine de, son zamanlar da yapılan çalışmalarda PKG iyi bir alternatif olabileceği vurgulandı(1, 2). SYNTAX çalışmasında CABG ve PKG grupları arasında bir yıllık sonuçlar arasında önemli fark izlenmedi(7). Son çalışmalara göre SYNTAX skoru düşük orta riskli anatomik yapıya sahip sol ana koroner arter lezyonlarında PKG, CABG ye 3 yıllık miyokard enfarktüsü(MI) ,stroke ve tüm nedenlere bağlı ölüm de non-inferior kriterini karşılamıştır.[4] Geniş popülasyonda yapılan çalışmalarda 5 yıllık mortalitede fark saptanmamıștır(8). Bu sonuçlara dayanarak dünya genelinde LMCA lezyonları için PKG yaklaşımı giderek artmaktadır.
Fakat 1201 hastayı içeren primer sonlanım noktası tüm nedenlere bağlı ölüm nonprosedürel $\mathrm{MI}$, inme ve tekrarlayan revaskülarizasyon olan NOBLE çalışmasına göre 5 yıllık tekrarlayan revaskülarizasyon, nonprosedürel $\mathrm{MI}$, stroke PKG kolunda daha yüksekti(5). Ancak mevcut vakada olduğu gibi kardiyak arrest veya kardiyojenik şok tablosu gelişen hastalarda olabildiğince hızlı müdahale etmek ve iskemi süresini kısaltmak amacıyla acil perkütan koroner girişim öncelikli tedavi seçeneği olarak düşünülebilir.

Son dönemde yapılan çalışmalarda özellikle stent teknolojisinin gelişmesi ile günlük pratikte acil vakalarda stentleme işleminin yüz güldürücü sonuçlar verdiği görülmektedir(7). İlaç kaplı stentlerin tercih edilmesi uzun dönem sonuçlar açısından önemlidir(6, 8, 9). Bizim vakamızda öncelikle bypass cerrahisi düşünülmesine rağmen gelişen kardiyak arrest sonucu hastanın kardiyopulmoner resusitasyon altında acilen anjiografi laboratuvarına alınıp stentleme işlemi uygulanmış ve komplikasyonsuz bir şekilde taburcu edilmiştir. Son dönemde elde edilen veriler bu gibi vakalarda tercih ettiğimiz yöntemin uygulanabilir ve uygun maliyetli olduğunu bunun yanı sıra kısa ve orta vadede sonuçlarının da kabul edilebilir düzeyde olduğunu göstermektedir.

\section{SONUÇ}

Yeni teknolojilerin gelişmesi, yeni jenerasyon daha efektif stentlerin kullanılması koroner içi görüntüleme yöntemleri ile LMCA lezyonlarına PKG sıklığı da artacaktır. Kardiyak arrest ile gelen uygun anatomiye sahip LMCA lezyonu bulunan hastalarda hızlı bir yaklaşım olarak PKG nin iyi bir tedavi seçeneği olacağı düşünülmelidir

\section{Çıkar Çatışması}

Yazarlar herhangi bir çıkar çatışması bildirmemiştir.

\section{KAYNAKLAR}

1.De Rosa, S., et al., Long-term outcomes of coronary artery bypass grafting versus stent- $\mathrm{PCl}$ for unprotected left main disease: a meta-analysis. BMC Cardiovasc Disord, 2017; 17: 240

2.Giacoppo, D., et al., Percutaneous Coronary Intervention vs Coronary Artery Bypass Grafting in Patients With Left Main Coronary Artery Stenosis: A Systematic Review and Meta-analysis. JAMA Cardiol, 2017;2:1079-88.

3. Hennekens, C.H., Increasing burden of cardiovascular disease: current knowledge and future directions for research on risk factors. Circulation, 1998; 97:1095-102.

4.Stone, G.W., et al., Everolimus-Eluting Stents or Bypass Surgery for Left Main Coronary Artery Disease. N Engl J Med, 2016;375:2223-35.

5.Mäkikallio, T., et al., Percutaneous coronary angioplasty versus coronary artery bypass grafting in treatment of unprotected left main stenosis (NOBLE): a prospective, randomised, open-label, non-inferiority trial. The Lancet, 2016 388: $2743-52$.

6.Jamieson, B.D. and E.R. Mariano, Thoracic and lumbar paravertebral blocks for outpatient lithotripsy. Journal of clinical anesthesia, 2007;19:149-51.

7.Morice, M.C., et al., Outcomes in patients with de novo left main disease treated with either percutaneous coronary intervention using paclitaxeleluting stents or coronary artery bypass graft treatment in the Synergy Between Percutaneous Coronary Intervention with TAXUS and Cardiac Surgery (SYNTAX) trial. Circulation, 2010;121: 2645-53.

8. Head, S.J., et al., Mortality after coronary artery bypass grafting versus percutaneous coronary intervention with stenting for coronary artery disease: a pooled analysis of individual patient data. Lancet, 2018;391:939-48.

9.Cohen, D.J., et al., Cost-effectiveness of percutaneous coronary intervention with drug-eluting stents versus bypass surgery for patients with 3-vessel or left main coronary artery disease: final results from the Synergy Between Percutaneous Coronary Intervention With TAXUS and Cardiac Surgery (SYNTAX) trial. Circulation, 2014;130:1146-57. 